\title{
Endogenous Activation of $\mu$ and $\delta$-1 Opioid Receptors Is Required for Long-Term Potentiation Induction in the Lateral Perforant Path: Dependence on GABAergic Inhibition
}

\author{
Clive R. Bramham and John M. Sarvey \\ Department of Pharmacology, Uniformed Services University of the Health Sciences, Bethesda, Maryland 20814-4799
}

Opioid peptides costored with glutamate have emerged as powerful regulators of long-term potentiation (LTP) induction in several hippocampal pathways. The objectives of the present study were twofold: (1) to identify which opioid receptor types $(\mu, \delta$, or $\kappa)$ regulate LTP induction at lateral perforant pathgranule cell synapses and (2) to test the hypothesis that endogenous opioids regulate LTP induction via modulation of GABAergic inhibition. LTP of lateral perforant path-evoked field EPSPs was induced selectively by high-frequency stimulation applied to the outer third of the molecular layer of the dentate gyrus of rat hippocampal slices. No changes in medial perforant path responses occurred. LTP was blocked when highfrequency stimulation was applied in the presence of the $\mu$ receptor antagonist CTAP, the selective $\delta$ - 1 receptor antagonist BNTX, or the $\delta$ - 1 and $\delta$-2 receptor antagonist naltrindole. By contrast, the $\kappa-1$ opioid receptor antagonist NBNI had no effect on LTP induction. The role of GABAergic inhibition was investigated by comparing the effect of naloxone on LTP induction in slices maintained in standard buffer and picrotoxincontaining buffer. Naloxone blocked LTP in standard buffer, whereas normal LTP was induced in picrotoxin-treated, disinhibited slices. Finally, NMDA receptor blockade completely inhibited LTP in both standard and disinhibited slices. The results show that $\mu$ and $\delta$ - 1 opioid receptors regulate LTP induction and that this mechanism critically depends on GABAergic inhibition. A key issue then becomes how endogenous opioids fine-tune the activity of intact inhibitory networks in the dentate gyrus, effectively gating synaptic plasticity in specific dendritic strata.

Key words: long-term potentiation; synaptic plasticity; opioid receptor; dentate gyrus; NMDA receptor; hippocampus
Opioid receptor-dependent long-term potentiation (LTP) provides perhaps the most clear-cut example of neuropeptide regulation of synaptic plasticity in the mammalian brain (Bramham, 1992; Bliss and Collingridge, 1993). Opioids are costored with glutamate in several hippocampal pathways, including the lateral perforant path (LPP) input to granule cells in the dentate gyrus, the LPP input to CA3 pyramidal cells, and the mossy fiber projection to CA3 pyramidal cells (Gall, 1981; Fredens et al., 1984; Bramham et al., 1990; Commons and Milner, 1995). In all of the these pathways, LTP induction is blocked by naloxone, an antagonist at all three types of opioid receptor, $\mu, \delta$, and $\kappa$ (Martin, 1983; Bramham et al., 1988, 1991b; Derrick et al., 1991, 1992; Xie and Lewis, 1991; Briendl et al., 1994; Williams and Johnston, 1996) [but see also Salin et al. (1995) regarding mossy fiber LTP]. LTP is induced by high-frequency stimulation (HFS), and, as seems to be generally the case for neuropeptides, release of opioid peptides requires HFS (Wagner et al., 1990; Hökfelt, 1991; Derrick and Martinez, 1994).

The types of opioid receptor that regulate LTP of the enkephalinergic LPP-granule cell pathway are currently an issue of de-

Received July 29, 1996; revised Sept. 24, 1996; accepted Sept. 26, 1996.

This work was supported by National Institutes of Health Grant NS23865 to J.M.S. We thank K. Commons for insightful discussions during the preparation of this manuscript and R. Berry, K. Pang, B. Srebro, and P. Voulalas for critical comments during the course of this work.

Correspondence should be addressed to Dr. John M. Sarvey, Department of Pharmacology, Uniformed Services University of the Health Sciences, 4301 Jones Bridge Road, Bethesda, MD 20814-4799.

Dr. Bramham's present address: Department of Physiology, University of Bergen, Årstadveien 19, N-5009 Bergen, Norway.

Copyright (C) 1996 Society for Neuroscience $0270-6474 / 96 / 168123-09 \$ 05.00 / 0$ bate. We reported previously that a selective $\delta$ receptor antagonist blocks LTP of LPP-evoked field EPSPs (fEPSPs) in the anesthetized rat (Bramham et al., 1991b), whereas an in vitro hippocampal slice study suggested a role for $\mu$, but not $\delta$, receptors in this effect (Xie and Lewis, 1995). However, the use of relatively high concentrations (micromolar) of $\mu$ and $\delta$ receptor antagonists in the latter study leaves open the possibility of confounding, nonspecific effects. $\kappa-1$ receptors clearly have been implicated in the suppression of LTP in the guinea pig perforant path, but the role of these receptors has not been investigated in the rat LPP (Terman et al., 1994).

The mechanism by which endogenous opioids facilitate LTP in the LPP is unknown. Exogenously applied $\mu$ and $\delta$ agonists inhibit GABA release from interneurons, resulting in enhanced excitability of pyramidal and granule cells, an effect known as disinhibition (Madison and Nicoll, 1988; Neumaier et al., 1988; Cohen et al., 1992; Xie et al., 1992; Piguet and North, 1993; Lupica, 1995), and a $\mu$ agonist was shown to facilitate LTP of the LPP-evoked population spike (Xie and Lewis, 1991). However, exogenous agonists do not necessarily mimic the actions of endogenous opioids. Whereas bath application activates opioid receptors widely distributed across the dentate gyrus (McLean et al., 1987; Commons and Milner, 1996a), endogenously released opioids are likely to act in a spatially restricted, concentration-dependent manner to activate specific subsets of $\mu, \delta$, or $\kappa$ receptors.

The main goals of the study were twofold: (1) to identify the opioid receptor types regulating LTP in the LPP using highly selective antagonists at pharmacologically relevant concentrations and (2) to determine whether or not endogenous opioids act via modulation of GABAergic inhibition. The latter was tested by 
comparing the effect of naloxone on LTP induction in control slices and disinhibited slices treated with picrotoxin, a $\mathrm{GABA}_{\mathrm{A}}$ channel blocker. If the disinhibition hypothesis is correct, pharmacological suppression of GABA-mediated inhibition would be expected to obviate the need for opioids.

A potential problem that we wanted to avoid in the present study was cross-stimulation of medial perforant path (MPP) fibers that border on the LPP in the outer molecular layer. We have, therefore, used very low stimulus intensities to induce LTP in the LPP and monitored pathway selectivity in all experiments by parallel recording of LPP and MPP-evoked fEPSPs across a range of low stimulus intensities.

A preliminary account of this work has been reported (Bramham and Sarvey, 1994).

\section{MATERIALS AND METHODS}

\section{Preparation of hippocampal slices}

Male Sprague Dawley rats (Taconic, Germantown, NY) weighing between 75 and $200 \mathrm{gm}$ were anesthetized with ketamine hydrochloride $(100-200 \mathrm{mg} / \mathrm{kg}$, i.p.). After decapitation, the brain was removed rapidly and placed in a Petri dish containing ice-cold artificial cerebrospinal fluid (ACSF) of the following composition (in $\mathrm{mM}$ ): $\mathrm{NaCl} \mathrm{125,} \mathrm{KCl} 3, \mathrm{CaCl}_{2}$ 2.4, $\mathrm{NaH}_{2} \mathrm{PO}_{4} 1.2, \mathrm{MgSO}_{4} 1.3, \mathrm{NaHCO}_{3} 26$, and dextrose 10 bubbled continuously with a gas mixture of $95 \% 0_{2} / 5 \% \mathrm{CO}_{2}$. The hippocampus was rapidly dissected free, and transverse slices ( $400 \mu \mathrm{m}$ thick) from the mid-dorsal hippocampus were cut on a McIlwain tissue chopper and transferred by paint brush to a modified Oslo interface chamber. The recording stage of the chamber consisted of a nylon mesh support overlaid with fine-grained filter paper for greater stability of recording. Slices were perfused continuously with bubbled ACSF at a rate of 3 $\mathrm{ml} / \mathrm{min}$ (Gilson Minipuls 2 peristaltic pump) and maintained at $31.5^{\circ} \mathrm{C}$. In experiments involving picrotoxin (PTX) perfusion the $\mathrm{MgSO}_{4}$ concentration was raised to $4 \mathrm{mM}$, and in most slices the CA3 region was cut away before the slices were chopped. PTX-containing buffer was perfused continuously, starting $65 \mathrm{~min}$ before collection of baseline responses.

\section{Electrodes and electrode placement}

After the slices were allowed to incubate for at least $1.5 \mathrm{hr}$, monopolar stimulating electrodes (Teflon-insulated stainless steel wire; diameter, 25 $\mu \mathrm{m})$ exposed only at the tip were placed on the surface of the slice in the outer and middle thirds of the molecular layer of the suprapyramidal (hidden) blade of the dentate gyrus for selective stimulation of the lateral (LPP) and medial perforant path (MPP), respectively (Dahl and Sarvey, 1989). The return path for the stimulating electrodes was an $\mathrm{Ag} / \mathrm{AgCl}$ ground wire in the bathing medium. Field potentials were recorded with glass micropipettes $(2-6 \mathrm{M} \Omega$ ) filled with $2 \mathrm{M} \mathrm{NaCl}$. The recording electrodes were placed at least $500 \mu \mathrm{m}$ from the stimulating electrodes along the trajectory of the perforant path fibers, and the distance between the electrode pairs in the middle and outer molecular layers was $\sim 150$ $\mu \mathrm{m}$. Recording electrodes were lowered to a distance of $80-100 \mu \mathrm{m}$ beneath the slice surface.

\section{Tests for assessing selective stimulation of the LPP and MPP}

The close proximity of the LPP and MPP fiber tracts in the molecular layer makes it important to ascertain the selectivity of stimulation, because cross-stimulation could occur. The positions of the stimulating and recording electrodes were adjusted to obtain maximal selectivity of stimulation, as described previously (Dahl and Sarvey, 1989). In the present study, three criteria were used to assess the selectivity of stimulation.

Depth profile. First, the fEPSP elicited by stimulation of the LPP or MPP should reverse polarity across the outer and middle third of the molecular layer. Thus, stimulation in one zone of the molecular layer should evoke a negative-going fEPSP in that layer, reflecting an inward current sink, and a positive-going potential in the other layer, reflecting an outward current source. The sharp polarity reversal of the waveforms over a distance of $150 \mu \mathrm{m}$ indicates a highly focal stimulation of LPP and MPP fibers.

Paired-pulse facilitation. The LPP exhibits paired-pulse facilitation of the fEPSP peak amplitude at interpulse intervals where the MPP-evoked fEPSP fails to show facilitation, thus providing a means to distinguish operationally between the two pathways (McNaughton, 1980; Colino and
Malenka, 1993). Paired-pulse tests were conducted at 20 and $80 \mathrm{msec}$ interpulse intervals. Slices were accepted for further study when the LPP showed facilitation of fEPSPs at the $80 \mathrm{msec}$ interval, while the MPPevoked fEPSPs in the same slice showed either no change or suppression. For slices used in control LTP experiments $(n=8)$, the LPP and MPP exhibited mean changes of fEPSP amplitude of $32.1 \pm 3.1 \%$ and $-9.42 \pm$ $6.4 \%$, respectively (see Table 1 ).

Effect of L-amino-2-phosphonobutyrate (L-AP4). A final test of selectivity performed in three slices was pharmacological. Previous in vitro and in vivo studies have shown that L-AP4, which stimulates L-AP4 glutamate receptors, selectively inhibits LPP-evoked fEPSPs (Koerner and Cotman, 1981; Bramham et al., 1991a). In agreement with these reports, perfusion with L-AP4 (100 $\mu \mathrm{M} ; n=3)$ inhibited LPP fEPSPs without affecting MPP responses. Both responses were eliminated by subsequent perfusion with $10 \mu \mathrm{m}$ of CNQX.

\section{Experimental protocol}

LPP and MPP fEPSPs were obtained at regular intervals for constructing both input-output curves (plots of the fEPSP slope as a function of stimulus strength) and time course plots on the basis of test pulses of constant stimulus strength. After stable fEPSPs were monitored for 30 min, an input-output curve was collected, followed by $20 \mathrm{~min}$ of recording at the test pulse intensity. Experimental groups then received drugcontaining ACSF, and controls received ACSF only. Test responses were collected during the first $20 \mathrm{~min}$ of drug perfusion, followed by an input-output curve during the next $5 \mathrm{~min}$. High-frequency stimulation (HFS; $100 \mathrm{~Hz}, 1 \mathrm{sec}$ ) then was applied to the LPP. Test responses were collected for $45 \mathrm{~min}$, and an input-output curve was obtained $40 \mathrm{~min}$ post-HFS. Standard ACSF was reintroduced 3 min post-HFS.

Input-output curves were considered a reliable method of assessing the selectivity of LTP induction in the LPP. Averaged responses (2 sweeps) were collected at six stimulus pulse durations. The stimulus pulse durations were selected in each slice to elicit fEPSPs ranging from just above threshold to a near-maximal fEPSP slope. These durations were 20, $30,40,50,70$, and $90 \mu \mathrm{sec}$ above the fEPSP threshold. Current intensity was kept constant in each slice and ranged from 5 to $40 \mu \mathrm{A}$ across slices. Stimulus pulse durations across slices ranged from 20 to $50 \mu \mathrm{sec}$ at the lowest pulse duration and from 80 to $110 \mu \mathrm{sec}$ at the highest duration. The pulse duration for test pulses and paired-pulse tests was set at either 30 or $40 \mu \mathrm{sec}$ above the fEPSP threshold. This pulse duration corresponded to the steepest part of the input-output curve for each slice and was considered to afford maximal sensitivity in detecting fEPSP slope changes. The stimulus strength for HFS of the LPP was set to evoke a maximal fEPSP slope; this intensity was at least $50 \mu \mathrm{A}$ below the population spike threshold. The threshold for eliciting a population spike in the LPP is much higher than in the MPP. As recorded in the granule cell layer, the LPP-evoked population spike typically appears on the descending phase of the positive field potential at intensities near $100 \mu \mathrm{A}, 100$ $\mu$ sec. Preliminary experiments showed that HFS applied at intensities above the population spike threshold frequently resulted in crossstimulation of the MPP, with LTP occurring in both pathways. Thus, low intensity stimulation was critical for obtaining selective LTP of the LPP.

\section{Drugs}

The following drugs were used: $\mathrm{D}(-)-2$-amino-5-phosphonopentanoate (AP5), L-amino-2-phosphonobutyrate (L-AP4), and 6-cyano-7nitroquinoxaline-2,3-dione (CNQX, Tocris Neuramin, Bristol, UK); 7-benzylidenenaltrexone hydrochloride (BNTX), naloxone hydrochloride, naltrindole hydrochloride, and nor-binaltorphimine dihydrochloride (NBNI, Research Biochemical International, Natick, MA); picrotoxin (Sigma, St. Louis, MO); and D-Phe-Cys-Tyr-Arg-Thr-Pen-Thr-NH ${ }_{2}$ (CTAP), a kind gift of Dr. V. Hruby, Tucson, Arizona (Kazmierski et al., 1988).

All drugs were dissolved in saline, and concentrated stock solutions were aliquoted in single doses, stored at $-80^{\circ} \mathrm{C}$, and diluted in ACSF immediately before use. All drugs were bath-applied to hippocampal slices at a rate of $3 \mathrm{ml} / \mathrm{min}$. The main concentration used for each selective antagonist was at least 50 times above the $K_{\mathrm{d}}$ value.

\section{Data analysis and statistics}

The signals were amplified, filtered (from $1 \mathrm{~Hz}$ to $10 \mathrm{kHz}$ ), digitized at 20 $\mathrm{kHz}$ (DAS-20 interface, Keithley Metrabyte, Taunton, MA), and stored to disk for off-line analysis with Labman software (kind gift of Dr. T. Teyler, NeuroScientific Laboratories, Rootstown, $\mathrm{OH}$ ). The initial slope of the fEPSP was used as a measure of synaptic efficacy. Slope values were 
A

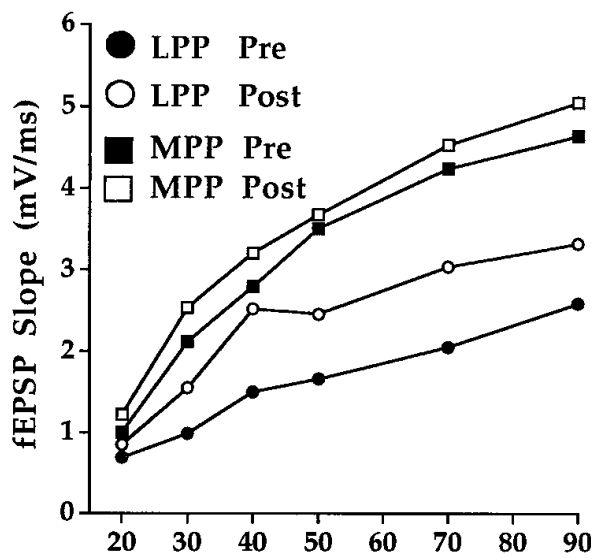

Stimulus Pulse Duration, $\mu$ s
B
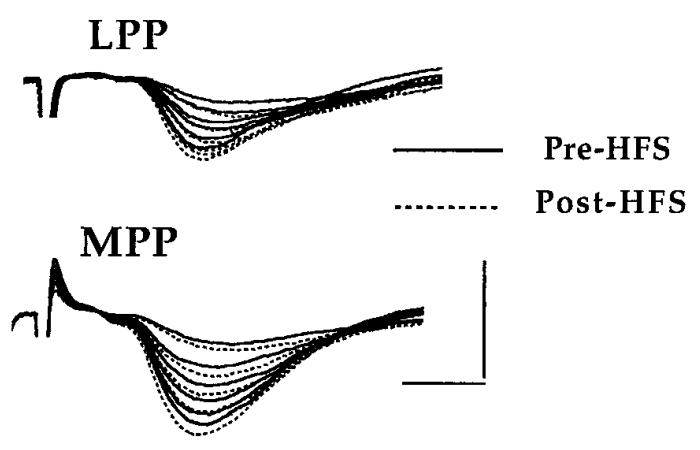

C

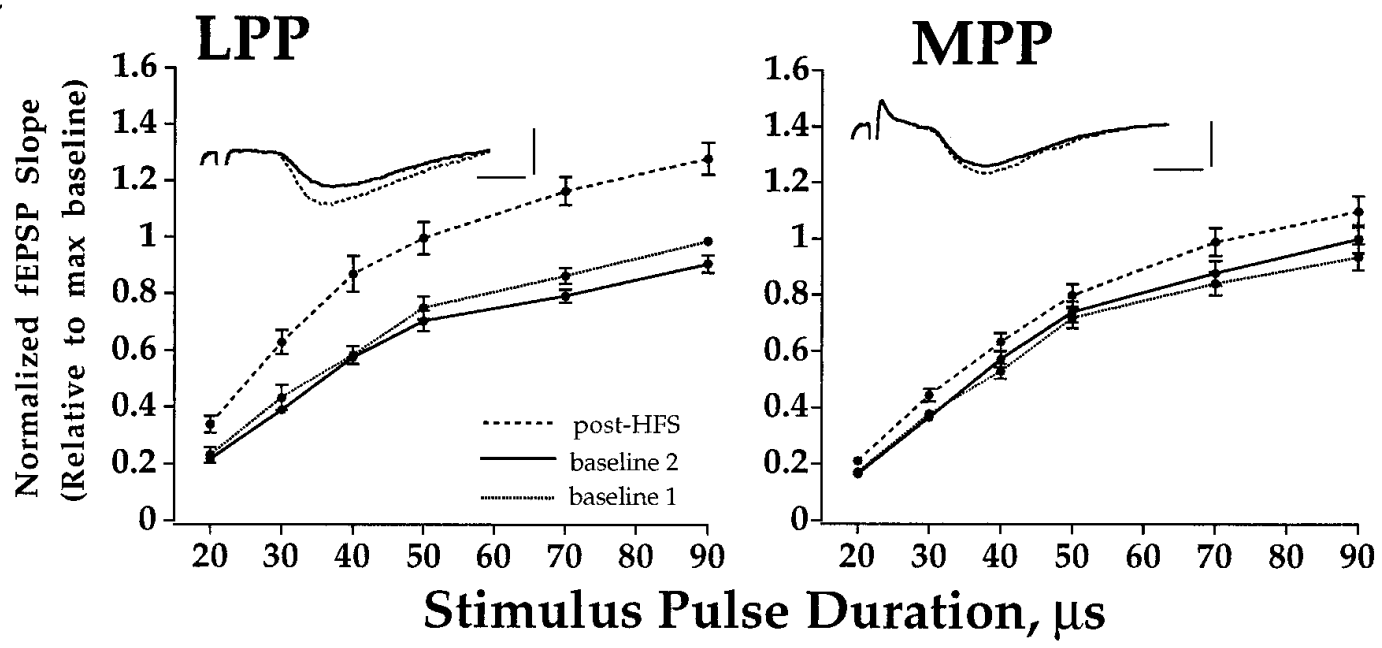

Figure 1. Selective induction of LTP in the LPP. $A$, Representative input-output curves on the basis of LPP and MPP responses obtained before and $40 \mathrm{~min}$ after HFS of the LPP. The fEPSP slope is plotted as a function of stimulus pulse duration. Response averages ( 2 sweeps/average) were collected at six stimulus pulse durations ranging from $20 \mu \mathrm{sec}$ above fEPSP threshold to $90 \mu \mathrm{sec}$ above threshold (near the maximum fEPSP slope). $B$, Field potential traces used to derive input-output curves in $A$. $C$, Control group input-output curves. Input-output curves were obtained during perfusion with standard ACSF (baseline 1, dotted line), 20 min after further perfusion in ACSF (baseline 2, solid line), and 40 min after HFS (post-HFS, dashed line) applied to the LPP. fEPSP slope values from each slice are normalized relative to the maximum value on the baseline 2 input-output curve collected immediately before HFS. Plots are mean \pm SEM $(n=8)$. Inset shows representative traces taken before (solid line) and after (dashed line) HFS. Horizontal bar, $2 \mathrm{msec}$; vertical bar, $3 \mathrm{mV}$.

normalized in each slice relative to the maximum fEPSP slope on the input-output curve collected immediately before HFS. Statistical analysis of drug and HFS effects was based on the raw input-output data and consisted of a within-group two-way ANOVA for repeated measures, followed by a post hoc Scheffé's test (STATISTICA package, StatSoft, Tulsa, OK). A probability of 0.05 was chosen as the level of statistical significance. For the time course plots, fEPSP slope values are expressed in percentage of baseline (all 12 pre-HFS responses). The magnitude of LTP was calculated as the mean percentage of increase above baseline for the last six time points in the time course (from 15 to 45 min post-HFS).

\section{RESULTS}

\section{Selective induction of LTP in the LPP}

Criteria used to assess selectivity of stimulation in response to single test pulses are described in Materials and Methods. The effect of HFS of the outer molecular layer on LPP and MPPevoked fEPSPs is shown in input-output curves in Figure 1, and the time course plots are given in Figure $2 A, B$. HFS of the LPP in slices receiving standard ACSF evoked a robust increase in the LPP-evoked fEPSPs $(n=8 ; p<0.05$, ANOVA and post hoc Scheffé's) but had no significant effect on MPP responses recorded from the same slices $(p>0.05)$. Thus, LTP was induced selectively in the LPP with no significant cross-stimulation of MPP fibers or induction of heterosynaptic effects.

\section{Endogenous activation of $\mu$ and $\delta-1$, but not $\kappa-1$, opioid receptors is required for LTP induction in the LPP}

The effects of selective opioid receptor antagonists on LTP induction in the LPP are shown in input-output curves (Fig. $2 A$ ) and time course plots (Fig. $2 B$ ). No significant change in LPP fEPSPs occurred when HFS was applied in the presence of CTAP, a 

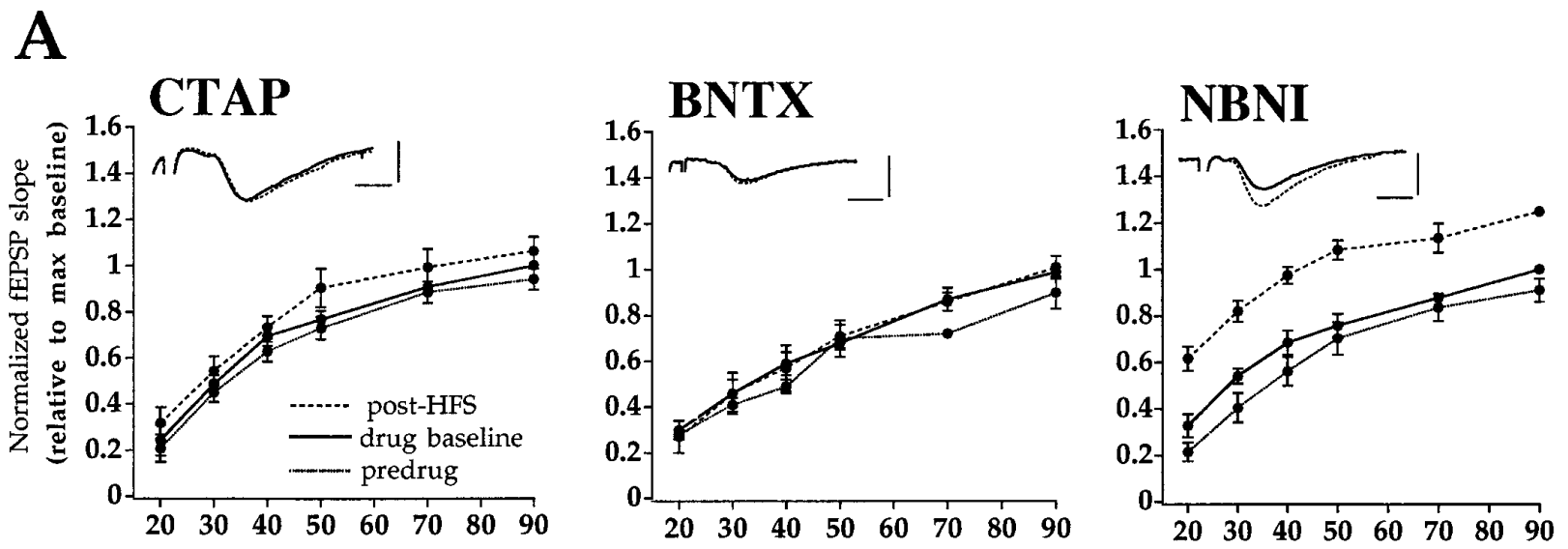

Stimulus Pulse Duration, $\mu$ s

B
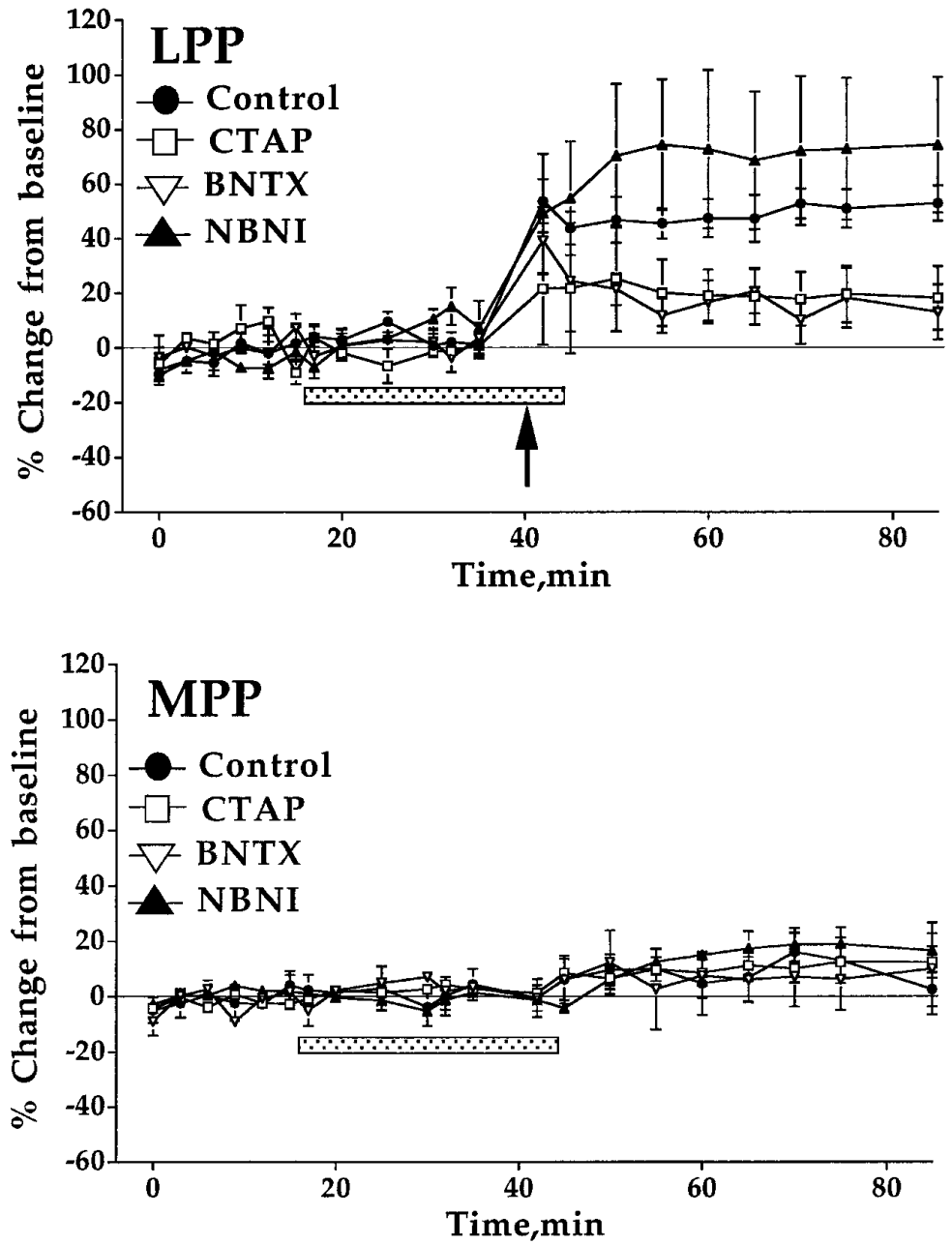

Figure 2. Activation of $\mu$ and $\delta$, but not $\kappa-1$, opioid receptors is required to induce LTP in the LPP. HFS was applied in the presence of selective antagonists for the $\mu$-opioid receptor $(C T A P, 100 \mathrm{nM} ; n=6)$, the $\delta$-1 opioid receptor $(B N T X, 100 \mathrm{nM} ; n=5)$, or the $\kappa-1$ opioid receptor $(N B N I, 60 \mathrm{nM}$; $n=5$ ). A, Input-output curves obtained during perfusion with standard ACSF (predrug, dotted line), 20 min after addition of drug (drug baseline, solid line), and 40 min after HFS (post-HFS, dashed line). HFS was applied immediately after obtaining the drug baseline input-output curve. Plots are group mean \pm SEM of fEPSP slope values normalized relative to the maximum value of the input-output curve collected immediately before HFS. Inset shows representative traces taken before (solid line) and $40 \mathrm{~min}$ post-HFS (dashed line). Horizontal bar, $2 \mathrm{msec}$; vertical bar, $3 \mathrm{mV}$. The time course of changes in LPP and MPP-evoked fEPSPs is shown in $B$ and $C$, respectively. Plots are group mean \pm SEM changes in fEPSP slope expressed in percentage of baseline. The period of drug perfusion is indicated by the stippled bar, and delivery of HFS to the LPP is indicated by an arrow. CTAP and BNTX both blocked LTP induction. LTP induced in the NBNI group was not significantly different from control. HFS of the LPP had no significant effect on MPP responses $(C)$. 
Table 1. Effect of picrotoxin on paired-pulse inhibition and facilitation in the LPP and MPP

\begin{tabular}{lrrrrl} 
& \multicolumn{1}{c}{$20 \mathrm{msec}$ IPI } & & & $80 \mathrm{msec}$ IPI & \\
\cline { 2 - 3 } \cline { 5 - 6 } & \multicolumn{1}{l}{ CON } & PTX & & CON & \multicolumn{1}{l}{ PTX } \\
\hline MPP & $-22.5 \pm 2.4$ & $-12.7 \pm 4.3$ & & $-9.42 \pm 6.4$ & $0.48 \pm 3.3$ \\
LPP & $9.76 \pm 5.1$ & $5.53 \pm 6.6$ & & $32.1 \pm 3.1$ & $16.7 \pm 2.8^{a}$
\end{tabular}

Percentage change \pm SEM in fEPSP amplitude relative to conditioning pulse.

${ }^{a}$ Significant difference from control group ( $t$ test independent samples, $p<0.01$.) Control, $n=8$; picrotoxin (PTX), $n=9$. IPI, Interpulse interval.

selective $\mu$ receptor antagonist, or BNTX $(n=5 ; 100 \mathrm{nM})$, a selective $\delta$ - 1 receptor blocker $(p>0.05)$. CTAP was equally effective in blocking LTP at concentrations of $100 \mathrm{nM}(n=6)$ and $500 \mathrm{~nm}(n=3)$. Naltrindole, a potent antagonist at both the $\delta-1$ and $\delta$ - 2 receptor subtypes, also blocked LTP induction. Similar effects were obtained at naltrindole concentrations of $50 \mathrm{~nm}(n=$ 9), $10 \mathrm{nM}(n=2)$, and $1 \mathrm{nM}(n=3)$. In contrast with the effect of $\mu$ and $\delta$ - 1 antagonists, normal LTP was observed in slices perfused with the selective $\kappa-1$ opioid receptor antagonist NBNI $(n=5 ; 60$ $\mathrm{nM})$. Input-output curve and time course data both showed no significant difference between controls and NBNI-perfused slices in the magnitude of LTP obtained $(p>0.05)$. None of the antagonists significantly affected baseline LPP or MPP-evoked responses. LTP was induced selectively in the LPP in all of these experiments (Fig. 2C). The results indicate a requirement for both $\mu$ and $\delta$ - 1 receptors in LTP induction.

\section{Effect of picrotoxin on paired-pulse inhibition and facilitation in the LPP and MPP}

Consistent with a loss of GABA-mediated inhibition, slices continuously perfused with ACSF containing PTX $(50 \mu \mathrm{M})$ exhibited a loss of paired-pulse inhibition of the population spike at the 20 msec interpulse interval in the both the LPP and MPP. At high stimulus intensities (typically $100 \mu \mathrm{A}, 100 \mu \mathrm{sec}$ ) this hyperexcitability manifested as multiple population spikes. However, at the low intensities used for eliciting fEPSPs in this study, no polysynaptic activity could be detected during the paired-pulse tests or the subsequent LTP experiments (see traces in Fig. $3 A, B$ ). The effects of PTX on paired-pulse tests for the fEPSP are summarized in Table 1. In the LPP at the $80 \mathrm{msec}$ interpulse interval the percentage of facilitation of the fEPSP amplitude was reduced significantly from $32.1 \pm 3.1 \%$ in controls to $16.7 \pm 2.8 \%$ in PTX-treated slices $(t$ test independent samples, $p<0.01)$. PTX had no effect on paired-pulse responses in the LPP at the $20 \mathrm{msec}$ interpulse interval and no effect on MPP-evoked fEPSPs at either interpulse interval. The results indicate that PTX strongly suppresses paired-pulse inhibition of the population spike in both pathways while selectively attenuating paired-pulse facilitation of the LPP-evoked fEPSP.

\section{The mechanism of opioid receptor-dependent LTP depends on GABAergic inhibition}

The role of GABAergic inhibition in opioid receptor-dependent LTP was investigated by comparing the effect of naloxone on LTP induction in slices maintained in standard buffer and PTXcontaining buffer. PTX perfusion commenced 80 min before the addition of naloxone. As expected, naloxone (5 $\mu \mathrm{M})$ blocked LTP induction in standard medium. In dramatic contrast to this, naloxone had no effect on LTP in PTX-treated, disinhibited slices. Similar results were obtained in input-output curve (Fig. $3 A, B$ ) and time course data (Fig. $3 C$ ). The failure of naloxone to block
LTP was not attributable to removal of the CA3 region in PTXtreated slices, because the same effect was obtained in intact slices. Control experiments showed that PTX treatment did not affect the amount of LTP obtained; the magnitude of LTP measured in time course plots was $49.5 \pm 6.7 \%$ in standard ACSF and $55.6 \pm 6.6 \%$ in PTX-containing ACSF (Fig. 3C). MPP-evoked fEPSPs were not affected significantly by HFS of the LPP in the presence of PTX (Fig. 3D), showing that LTP remained pathwayspecific in the disinhibited slice.

\section{LTP induction in the LPP of hippocampal slices is NMDA receptor-dependent}

As shown in Figure 4, LTP induction was blocked completely when HFS was applied in the presence of the NMDA receptor antagonist AP5 (20 $\mu \mathrm{M} ; n=8)$. Thus, LPP LTP is both NMDA and opioid receptor-dependent in hippocampal slices. Finally, AP5 also was found to block LTP in two slices perfused with PTX, indicating that, under conditions in which opioid receptors are not required, LTP remains completely NMDA receptor-dependent.

\section{DISCUSSION}

We have used methods for selective stimulation and recording of LPP and MPP-evoked synaptic potentials in the dentate gyrus to identify which types of opioid receptor regulate LTP induction in the LPP and to investigate the role of GABAergic inhibition. The novel findings of the study include the following: (1) endogenous activation of $\mu$ and $\delta$-1 opioid receptors (but not $\kappa-1$ ) is required for LTP induction, and (2) endogenous opioid peptides regulate LTP indirectly, via modulation of GABAergic inhibition.

\section{Endogenous activation of both $\mu$ and $\delta$-1 opioid receptors is required for LTP induction}

On the basis of the effects of highly selective $\mu$ (CTAP) and $\delta$ receptor antagonists (BNTX and naltrindole), we provide the first evidence that endogenous activation of both receptor types is required in LTP of the LPP. Taken together with a previous in vivo study that used the $\delta$ blocker ICI 175864 (Bramham et al., $1991 b)$, the critical role of $\delta$ receptors in LPP LTP induction seems clear. Furthermore, because BNTX blocks $\delta$ - 1 receptors with little or no antagonist activity at $\delta-2$ receptors (Portoghese et al., 1992; Sofuoglu et al., 1993; Buzas et al., 1994), the present results identify a role for the $\delta-1$ receptor subtype in LTP. Xie and Lewis (1995) suggested that $\mu$, but not $\delta$, receptors are involved in LTP of the LPP-evoked fEPSP. However, micromolar concentrations of $\delta$ and $\mu$ antagonists were used in the latter study. We have used concentrations in the nanomolar range, which we consider to be pharmacologically more appropriate. Another difference is that Xie and Lewis induced LTP in the LPP by using stimulus intensities above the population spike threshold, whereas we have used intensities well below the population spike threshold. In our hands, subthreshold stimulation is needed to obtain LTP in the LPP without cross-stimulating, and inducing LTP in, MPP fibers. An intriguing possibility is that low intensity HFS recruits both $\mu$ and $\delta$ receptor mechanisms, whereas high intensity stimulation leads to a predominantly $\mu$ receptor-mediated form of LTP.

\section{Lack of a role for $\kappa-1$ opioid receptors in LTP of the LPP in the rat dentate gyrus}

Studies in the guinea pig have led to the proposal that dynorphin released from granule cell dendrites during HFS of the perforant path acts on presynaptic $\kappa-1$ receptors to inhibit glutamate release and suppress LTP induction (Wagner et al., 1993; Drake et al., 1994; Simmons et al., 1994). By blocking this retrograde message, 
A

Figure 3. Opioid peptides regulate LTP induction by a mechanism that depends on GABAergic inhibition. $A$, HFS was applied in the presence of standard ACSF (control; $n=8$ ) or ACSF containing picrotoxin $(P T X, 50 \mu \mathrm{M}$; $n=4)$. Input-output curves were obtained during perfusion with standard or PTX containing ACSF (baseline 1, dotted line), $20 \mathrm{~min}$ after further perfusion in this medium (baseline 2, solid line), and 40 min after HFS (post-HFS, dashed line) applied to the LPP. B, HFS was applied in the presence of naloxone ( $N L X, 5$ $\mu \mathrm{M})$ in slices continuously perfused with standard ACSF $(n=8)$ or PTX containing ACSF $(n=5)$. Plots are input-output curves obtained during perfusion with standard or PTX containing ACSF (predrug, dotted line), $20 \mathrm{~min}$ after addition of naloxone (drug baseline, solid line), and 40 min after HFS ( post-HFS, dashed line). PTX perfusion commenced $80 \mathrm{~min}$ before the addition of naloxone. Inset shows representative traces taken before (solid line) and 40 min post-HFS (dashed line). All input-output curves are group mean \pm SEM of fEPSP slope values normalized relative to the maximum value of the input-output curve collected immediately before HFS. Horizontal bar, 2 msec; vertical bar, $3 \mathrm{mV}$. $C$, Time course of changes in LPP-evoked fEPSPs. Plots are group mean \pm SEM changes in fEPSP slope expressed in percentage of baseline. The period of drug perfusion is indicated by the stippled bar, and delivery of HFS to the LPP is indicated by an arrow. Perfusion with PTX abolished the ability of naloxone to block LTP. $D$, Time course of changes in MPP-evoked fEPSPs after HFS of the LPP in the presence of naloxone in slices perfused in standard ACSF or PTX containing ACSF. Note that LTP was induced selectively in LPP fibers in PTX-containing medium.

\section{Control}

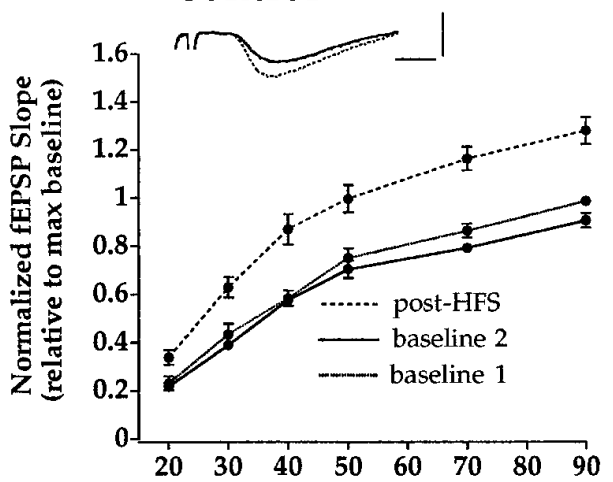

B

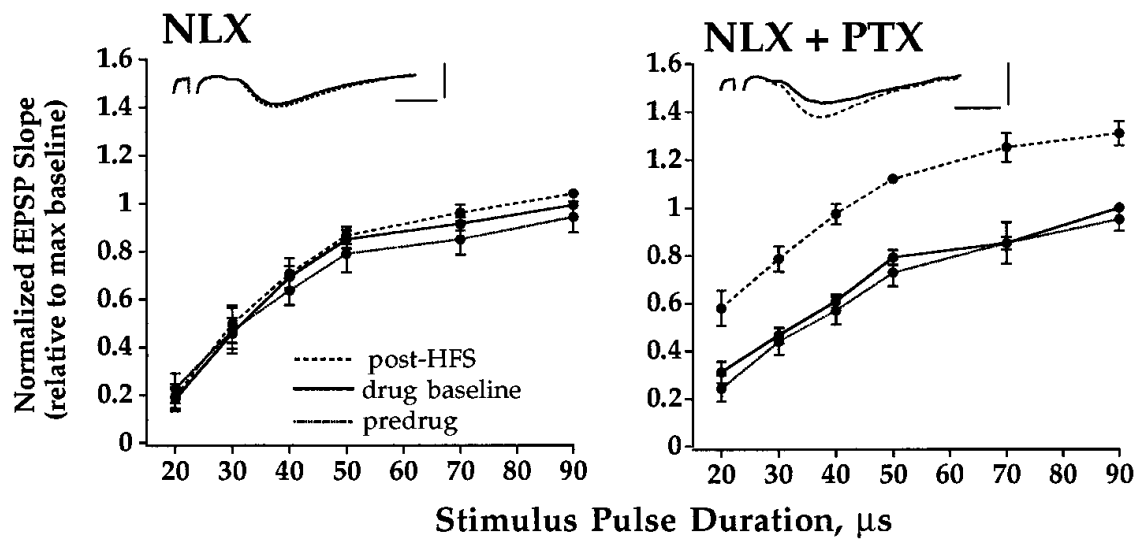

C
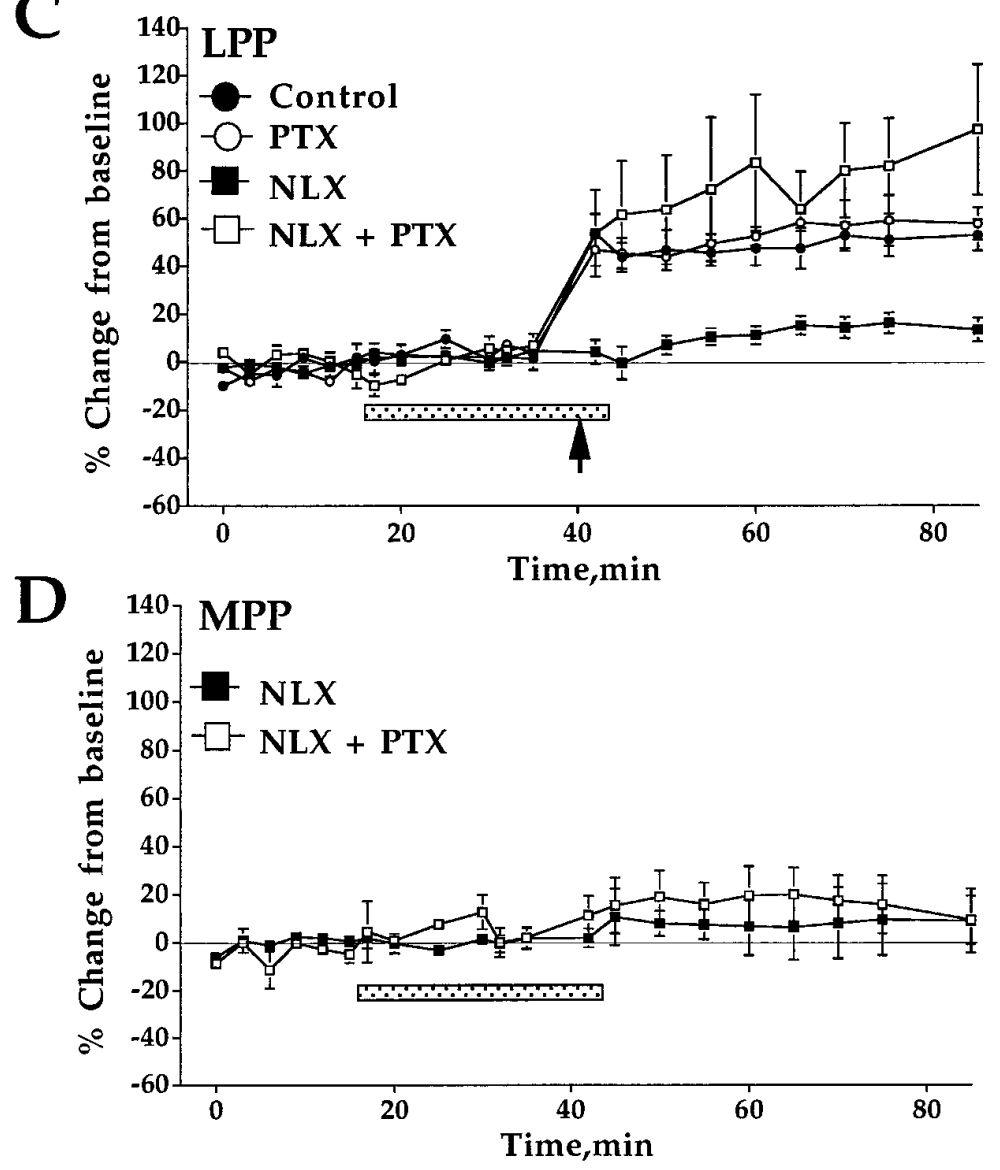

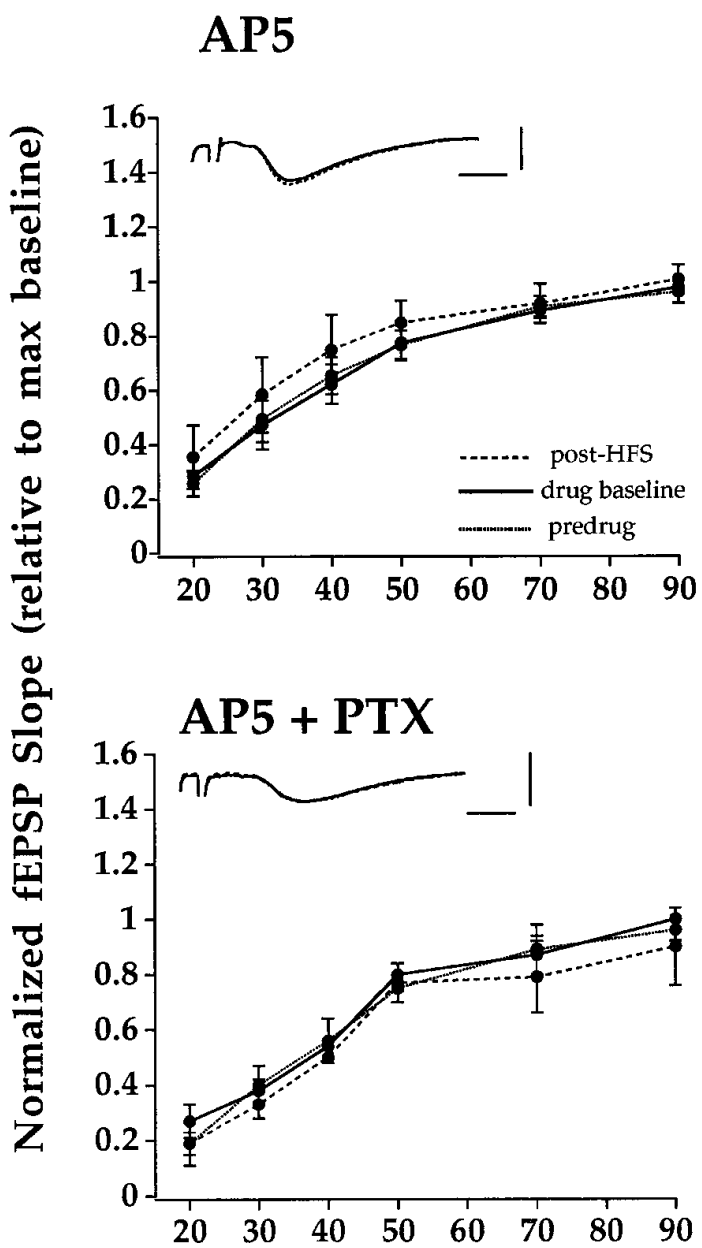

\section{Stimulus Pulse Duration, $\mu$ s}

Figure 4. NMDA receptor activation is required to induce LTP of LPPevoked fEPSPs in both standard and PTX-containing medium. HFS was applied in the presence of AP5 $(20 \mu \mathrm{M})$ in slices perfused with standard $\operatorname{ACSF}(n=9)$ or PTX containing $\operatorname{ACSF}(n=2)$. Input-output curves were obtained during perfusion with standard or PTX containing ACSF (baseline, dotted line), 20 min after addition of AP5 (drug baseline, solid line), and $40 \mathrm{~min}$ after HFS (post-HFS, dashed line). Plots are group mean \pm SEM of fEPSP slope values normalized relative to the maximum value of the input-output curve collected immediately before HFS. PTX perfusion commenced 80 min before the addition of AP5. Inset shows representative traces taken before (solid line) and $40 \mathrm{~min}$ post-HFS (dashed line). Horizontal bar, $2 \mathrm{msec}$; vertical bar, $3 \mathrm{mV}$.

treatment with NBNI facilitates LTP (Terman et al., 1994). The present results showing no effect of NBNI indicate that this particular mechanism does not operate in the rat LPP. On the other hand, leu-enkephalin is stored in granule cell dendrites of the rat, and the possibility that it has a retrograde function analogous to dynorphin in the guinea pig needs to be considered (Commons and Milner, 1995).

\section{Evidence that opioid receptor-dependent LTP is regulated by GABAergic inhibition}

One straightforward hypothesis for opioid receptor-dependent LTP is that opioid peptides released during HFS cause a transient suppression of GABA-mediated inhibition. The loss of inhibition would boost postsynaptic depolarization on granule cells, enabling voltage-dependent effects such as NMDA receptor activation at LPP-granule cell synapses. Figure 5 shows a schematic depiction

\section{Baseline}

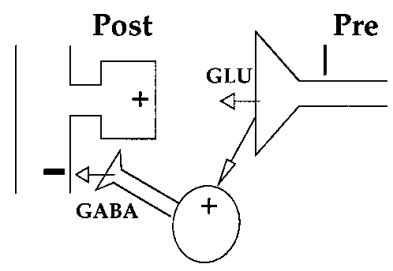

\section{Induction}

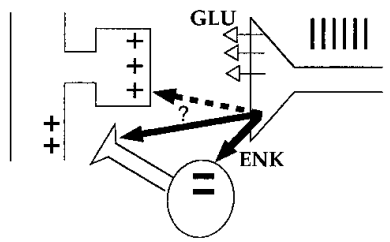

- hyperpolarization

+ depolarization

Figure 5. Schematic depiction of the disinhibition hypothesis of opioid receptor-dependent LTP. During HFS, enkephalins and glutamate are co-released from terminals of the LPP. Enkephalins activate $\mu$ - and $\delta$ opioid receptors on GABAergic interneurons, resulting in a transient suppression of GABA release during HFS. The loss of inhibition boosts depolarizing events on granule cells, enabling voltage-dependent events such as NMDA receptor activation. Plus signs $(+)$ represent depolarization; minus signs $(-)$ represent hyperpolarization. The site of enkephalin action (thick arrows) during LTP induction has not been established. Activation of $\delta$ receptors located on GABA terminals would afford restricted, local control of inhibition on granule cell dendrites. Activation of opioid receptors located at LPP-granule synapses (dashed arrow) is unlikely to be involved in induction but could still be important in establishing late-phase LTP.

of the "disinhibition hypothesis" of opioid receptor-dependent LTP. If endogenous opioids control LTP by suppressing GABAergic inhibition, then pharmacological suppression of GABA-mediated inhibition would be expected to obviate the need for opioids. The present results strongly support the disinhibition hypothesis; naloxone blocked LTP under normal conditions but failed to block LTP in disinhibited slices. One mechanism by which the disinhibition could be targeted to the LPP is if enkephalins act locally on GABA terminals to inhibit GABA release, as suggested by recent anatomical data (Commons and Milner, 1996b). The abolition of naloxone-sensitive LTP also has been shown by Xie and Lewis (1995), but there are significant methodological differences between that study and ours. The most important difference is the use in the present experiments of low stimulus intensities and dual recording of LPP and MPP responses. The strength of associative interactions between the LPP and MPP is greatly facilitated under disinhibitory conditions (Tomasulo et al., 1993; Zhang and Levy, 1993); LTP in simultaneously active MPP afferents and heterosynaptic long-term depression (LTD) in inactive MPP afferents are both enhanced. In the present study, LPP LTP was induced in standard and disinhibited slices without detectable cross-stimulation of MPP fibers and without inducing heterosynaptic LTD. Heterosynaptic LTD commonly is seen in vivo; thus, the absence of heterosynaptic LTD in slices clearly points to a difference between preparations (Bear and Abraham, 1996).

Failure of naloxone to block LTP in the LPP also has been reported to occur in PTX-treated guinea pig hippocampal slices 
(Hanse and Gustafsson, 1992). This may fit with a disinhibitory mechanism, but it remains to be seen whether opioid receptordependent LTP exists in standard slices in the absence of PTX. Given the differences between rat and guinea pig dentate gyrus in terms of the distribution of enkephalins, dynorphins, and their receptors (McLean et al., 1987, Tempel and Zukin, 1987; Sharif et al., 1989), a species difference in opioid regulation of LPP LTP would not be surprising.

Although enkephalin effects on interneurons offer the most parsimonious explanation for the present findings, we cannot rule out a direct action of enkephalins on the glutamatergic nerve terminal or granule cell dendrite. Indeed, a subpopulation of $\delta$ opioid receptors has been localized immunocytochemically to dendritic spines of excitatory synapses on granule cells (Commons and Milner, 1996a). What is the function of these receptors? Our results indicate that if opioids act directly at LPP synapses these effects are either (1) mimicked by blocking $\mathrm{GABA}_{\mathrm{A}}$ receptors or (2) unnecessary for LTP induction. There is no evidence to support the former; $\mu$ and $\delta$ agonists hyperpolarize granule cells, whereas PTX facilitates dendritic depolarization (Piguet and North, 1993). A direct action of opioids at LPP-granule cell synapses is therefore unlikely to mediate LTP induction. Alternatively, activation of these receptors during HFS could be important in establishing a late, mRNA synthesis-dependent phase of LTP. A direct resolution of the site of opioid action will require intracellular recording from interneurons and granule cells during the LTP induction event.

\section{The NMDA receptor controversy: a matter of in vitro versus in vivo?}

In agreement with previous work in standard (Xie and Lewis, 1991) and disinhibited slices (Hanse and Gustafsson, 1991; Colino and Malenka, 1993), we found LTP induction in the LPP to be completely NMDA receptor-dependent. By establishing the selectivity of LPP LTP in this study in both standard and disinhibited slices, we can exclude the possibility of contamination by MPP LTP, which is known to be NMDA receptor-dependent. The in vitro findings contrast with in vivo studies reporting no effect of competitive NMDA receptor antagonists on LTP of LPP-evoked fEPSPs in the dentate gyrus (Bramham et al., 1991a; Reyes et al., 1994) and CA3 region (Derrick et al., 1993).

We would like to emphasize differences between in vitro and in vivo preparations that may help to resolve this controversy. First, electrophysiological and anatomical evidence suggests that the inhibitory network is compromised in hippocampal slices (Halasy and Somogyi, 1993; Han et al., 1993; Buckmaster and Schwartzkroin, 1995; Sloviter and Brisman, 1995). Because interneuronal dendrites and axons are oriented perpendicular to the plane of transverse hippocampal slices, interneuronal circuits are disrupted selectively in this preparation, and the loss of GABAergic inhibition would be expected to promote NMDA receptor activation. Second, parameters for LTP induction in the slice are of lower frequency and longer duration $(100 \mathrm{~Hz}, 1 \mathrm{sec})$ than the burst stimulation $(400 \mathrm{~Hz}, 20 \mathrm{msec})$ typically used in anesthetized and freely moving rats. Perhaps the $400 \mathrm{~Hz}$ burst stimulation used in vivo, coupled with a tighter control of GABAergic inhibition on granule cell dendrites, leads to a greater contribution of dihydropyridine-sensitive voltage-dependent calcium channels, similar to that described in the hippocampal CA1 field and visual cortex (Grover and Teyler, 1990; Aroniadou et al., 1993), whereas $100 \mathrm{~Hz}$ stimulation, coupled with a looser inhibitory control, favors induction of purely NMDA receptor-dependent LTP. One intriguing consideration for future studies in behaving rats is that the type of opioid receptor-dependent LTP expressed (NMDA or non-NMDA) depends on the level of inhibitory network activity at the time of LPP stimulation.

\section{Perspectives}

In the LPP of the rat hippocampal slice, LTP induction seems to be controlled by $\mu$ and $\delta$ opioid receptors acting in concert to suppress GABAergic inhibition and facilitate NMDA receptor activation in specific dendritic strata. This contrasts with the situation in mossy fibers of the CA3 region where $\mu$ opioid receptors mediate LTP induction by a mechanism requiring neither suppression of GABAergic inhibition nor activation of NMDA receptors in vitro or in vivo (Harris and Cotman, 1986; Derrick et al., 1992; Johnston et al., 1992; Williams and Johnston, 1996). Clearly, more than one form of opioid receptor-dependent LTP exists in the hippocampus. Among the most pressing issues are to determine how opioids fine-tune the activity of inhibitory networks in the dentate gyrus and to identify the presumably unique functions subserved by opioid receptor-dependent LTP.

\section{REFERENCES}

Aroniadou VA, Maillis A, Stefanis CC (1993) Dihydropyridine-sensitive calcium channels are involved in the induction of $N$-methyl-D-aspartate receptor-independent long-term potentiation in visual cortex of adult rats. Neurosci Lett 151:77-80.

Bear MF, Abraham WC (1996) Long-term depression in hippocampus. Annu Rev Neurosci 19:437-462.

Bliss TVP, Collingridge GL (1993) A synaptic model for memory: longterm potentiation in the hippocampus. Nature 361:31-39.

Bramham CR (1992) Opioid receptor-dependent long-term potentiation: peptidergic regulation of synaptic plasticity in the hippocampus. Neurochem Int 20:441-455.

Bramham CR, Sarvey J (1994) Delta and mu opioid receptor activation is required to induce LTP in the lateral perforant path of normal, but not disinhibited, rat hippocampal slices. Soc Neurosci Abstr 20:623.11.

Bramham CR, Errington ML, Bliss TVP (1988) Naloxone blocks the induction of long-term potentiation in the lateral but not in the medial perforant pathway of the anesthetized rat. Brain Res 449:352-356.

Bramham CR, Torp R, Zhang N, Storm-Mathisen J, Ottersen OP (1990) Distribution of glutamate-like immunoreactivity in excitatory hippocampal pathways: a semiquantitative electron microscopic study in rats. Neuroscience 39:405-417.

Bramham CR, Milgram NW, Srebro B (1991a) Activation of AP5sensitive NMDA receptors is not required to induced LTP of synaptic transmission in the lateral perforant path. Eur J Neurosci 3:1300-1308.

Bramham CR, Milgram NW, Srebro B (1991b) Delta opioid receptor activation is required to induce LTP of synaptic transmission in the lateral perforant path in vitro. Brain Res 567:42-50.

Briendl A, Derrick BE, Rodriguez SB, Martinez Jr JL (1994) Opioid receptor-dependent long-term potentiation at the lateral perforant path-CA3 synapse in rat hippocampus. Brain Res Bull 33:17-24.

Buckmaster PS, Schwartzkroin PA (1995) Interneurons and inhibition in the dentate gyrus of the rat in vivo. J Neurosci 15:774-789.

Buzas B, Izenwasser S, Portoghese PS, Cox BM (1994) Evidence for delta opioid receptor subtypes regulating adenylyl cyclase activity in rat brain. Life Sci 54:101-106.

Cohen GA, Doze VA, Madison DV (1992) Opioid inhibition of GABA release from presynaptic nerve terminals of rat hippocampal interneurons. Neuron 9:325-335.

Colino A, Malenka RC (1993) Mechanisms underlying induction of longterm potentiation in rat medial and lateral perforant paths in vitro. J Neurophysiol 69:1150-1159.

Commons KG, Milner TA (1995) Ultrastructural heterogeneity of enkephalin-containing terminals in the rat hippocampal formation. J Comp Neurol 358:324-342.

Commons KG, Milner TA (1996a) Cellular and subcellular localization of delta opiate receptor immunoreactivity in the rat dentate gyrus. Brain Res, in press. 
Commons KG, Milner TA (1996b) Ultrastructural relationships between leu-enkephalin and GABA-containing neurons differ within the hippocampal formation. Brain Res 724:1-15.

Dahl D, Sarvey JM (1989) Norepinepherine induces pathway-specific long-lasting potentiation and depression in the hippocampal dentate gyrus. Proc Natl Acad Sci 86:4776-4780.

Derrick BE, Martinez Jr JL (1994) Opioid receptor activation is one factor underlying the frequency dependence of mossy fiber LTP induction. J Neurosci 14:4359-4367.

Derrick BE, Weinberger SB, Martinez Jr JL (1991) Opioid receptors are involved in an NMDA receptor-independent mechanism of LTP induction at hippocampal mossy fiber-CA3 synapses. Brain Res Bull 27:219-223.

Derrick BE, Rodriguez SB, Lieberman DN, Martinez Jr JL (1992) Mu opioid receptors are associated with the induction of hippocampal mossy fiber long-term potentiation. J Pharm Exp Ther 263:725-733.

Derrick BE, Barea-Rodriguez E, Martinez Jr JL (1993) LTP at lateral path perforant path CA3 synapses is mu opioid receptor-dependent, NMDA receptor-independent, and relatively long-lasting. Soc Neurosci Abstr 19:1326.

Drake CT, Terman GW, Simmons ML, Milner TA, Kunkel DD, Schwartzkroin PA, Chavkin C (1994) Dynorphin opioids present in dentate granule cells may function as retrograde inhibitory neurotransmitters. J Neurosci 14:3736-3750.

Fredens K, Stengaard-Pedersen K, Larsson L-I (1984) Localization of enkephalin and cholecystokinin immunoreactivities in the perforant path terminal fields of the rat hippocampal formation. Brain Res 304:255-263.

Gall C, Brecha N, Karten HJ, Chang K-J (1981) Localization of enkephalin-like immunoreactivity to identified axonal and neuronal populations of the rat hippocampus. J Comp Neurol 198:335-350.

Grover LM, Teyler TJ (1990) Two components of long-term potentiation induced by different patterns of afferent activation. Nature 347:477-479.

Halasy K, Somogyi P (1993) Subdivisions in the multiple GABAergic innervation of granule cells in the dentate gyrus of the rat hippocampus. Eur J Neurosci 5:411-429.

Han Z-S, Buhl EH, Lorinczi Z, Somogyi P (1993) A high degree of spatial selectivity in the axonal and dendritic domains of physiologically identified local-circuit neurons in the dentate gyrus of the rat hippocampus. Eur J Neurosci 5:395-410.

Hanse E, Gustafsson B (1992) Long-term potentiation and field EPSPs in the lateral and medial perforant paths in the dentate gyrus in vitro: a comparison. Eur J Neurosci 4:1191-1201.

Harris EW, Cotman CW (1986) Long-term potentiation of guinea pig mossy fiber responses is not blocked by $N$-methyl-D-aspartate antagonists. Neurosci Lett 70:132-137.

Hökfelt T (1991) Neuropeptides in perspective: the last ten years. Neuron 7:867-879.

Johnston D, Williams S, Jaffe D, Gray R (1992) NMDA-receptorindependent long-term potentiation. Annu Rev Physiol 54:489-505.

Kazmierski W, Wire WS, Lui GK, Knapp RJ, Shook J, Burks TF, Yamamura HI, Hruby VJ (1988) Design and synthesis of somatostatin analogues with topographical properties that lead to highly potent and specific mu opioid receptor antagonists with greatly reduced binding at somatostatin receptors. J Med Chem 31:2170-2177.

Koerner JF, Cotman CW (1981) Micromolar L-2-aminophosphonobutyric acid selectively inhibits perforant path synapses from the lateral entorhinal cortex. Brain Res 216:192-198.

Lupica CR (1995) Delta and mu enkephalins inhibit spontaneous GABA-mediated IPSCs via a cyclic AMP-independent mechanism in the rat hippocampus. J Neurosci 15:737-749.

Madison DV, Nicoll RA (1988) Enkephalin hyperpolarizes interneurones in the rat hippocampus. J Physiol (Lond) 398:123-130.
Martin MR (1983) Naloxone and long-term potentiation of hippocampal CA3 field potentials in vitro. Neuropeptides 4:45-50.

McLean S, Rothman RB, Jacobson AE, Rice KC, Herkenkam M (1987) Distribution of opiate receptor subtypes and enkephalin and dynorphin immunoreactivity in the hippocampus of squirrel, guinea pig, rat, and hamster. J Comp Neurol 255:497-510.

McNaughton BL (1980) Evidence for two physiologically distinct perforant pathways to the fascia dentata. Brain Res 199:1-19.

Neumaier JF, Mailheau S, Chavkin C (1988) Opioid receptor-mediated responses in the dentate gyrus and CA1 region of the rat hippocampus. J Pharmacol Exp Ther 244:564-570.

Piguet P, North RA (1993) Opioid actions at mu and delta receptors in the rat dentate gyrus in vitro. J Pharmacol Exp Ther 266:1139-1146.

Portoghese PS, Sultana M, Nagase H, Takemori AE (1992) A highly selective $\delta_{1}$-opioid receptor antagonist: 7-benzylidenenaltrexone. Eur J Pharmacol 218:195-196.

Reyes JA, Derrick BE, Martinez Jr JL (1994) Lateral perforant pathdentate gyrus LTP is dependent on opioid receptor activation. Soc Neurosci Abstr 20:373.24.

Salin PA, Weisskopf MG, Nicoll RA (1995) A comparison of the role of dynorphin in the hippocampal mossy fiber pathway in the guinea pig and rat. J Neurosci 15:6939-6945.

Sharif NA, Hughes J (1989) Discrete mapping of brain mu and delta opioid receptors using selective peptides: quantitative autoradiography, species differences, and comparison with kappa receptors. Peptides 10:499-522.

Simmons ML, Terman GW, Drake CT, Chavkin C (1994) Inhibition of glutamate release by presynaptic $\kappa_{1}$-opioid receptors. J Neurophysiol 72:1697-1705.

Sloviter RS, Brisman JL (1995) Lateral inhibition and granule cell synchrony in the rat hippocampal dentate gyrus. J Neurosci 15:811-820.

Sofuoglu M, Portoghese PS, Takemori AE (1993) 7-Benzylidenenaltrexone (BNTX): a selective $\delta$-1 opioid receptor antagonist in the mouse spinal cord. Life Sci 52:769-775.

Tempel A, Zukin RS (1987) Neuroanatomical patterns of the mu, delta, and kappa opioid receptors of rat brain as determined by quantitative in vitro autoradiography. Proc Natl Acad Sci USA 84:4308-4312.

Terman GW, Wagner JJ, Chavkin C (1994) Kappa opioid inhibits induction of long-term potentiation in the dentate gyrus of the guinea pig hippocampus. J Neurosci 14:4740-4747.

Tomasulo RA, Ramirez JJ, Steward O (1993) Synaptic inhibition regulates associative interactions between afferents during the induction of long-term potentiation and depression. Proc Natl Acad Sci USA 90:11578-11582.

Wagner JJ, Caudle RM, Neumaier JF, Chavkin C (1990) Stimulation of endogenous opioid release displaces $\mu$ receptor binding in rat hippocampus. Neuroscience 37:45-53.

Wagner JJ, Terman GW, Chavkin C (1993) Endogenous dynorphins inhibit excitatory neurotransmission and block LTP induction in the hippocampus. Nature 363:451-454.

Williams SH, Johnston D (1996) Actions of endogenous opioids on NMDA receptor-independent long-term potentiation in area CA3 of the hippocampus. J Neurosci 16:3652-3660.

Xie CW, Lewis DV (1991) Opioid-mediated facilitation of long-term potentiation at the lateral perforant path-dentate granule cell synapse. J Pharmacol Exp Ther 256:289-296.

Xie CW, Lewis DV (1995) Depression of LTP in rat dentate gyrus by naloxone is reversed by $\mathrm{GABA}_{\mathrm{A}}$ blockage. Brain Res 688:56-60.

Xie CW, Morrisett RA, Lewis DV (1992) Mu opioid receptor-mediated modulation of synaptic currents in dentate granule cells of rat hippocampus. J Neurophysiol 68:1113-1120.

Zhang DX, Levy WB (1993) Bicuculline permits the induction of longterm depression by heterosynaptic, translaminar conditioning in the hippocampal dentate gyrus. Brain Res 613:309-312. 